\title{
Compressive Properties of Expanded Perlite Based Particulate Composite for the Application in Building Insulation Board
}

\author{
Partho Adhikary ${ }^{1}$, Md Arifuzzaman ${ }^{2, *}$ and Emamul Kabir ${ }^{2}$ \\ ${ }^{1}$ Department of Biomedical Engineering, Khulna University of Engineering \& Technology, Khulna-9203, BANGLADESH \\ ${ }^{2}$ Department of Mechanical Engineering, Khulna University of Engineering \& Technology, Khulna-9203, BANGLADESH
}

Received: March 26, 2020, Revised: March 31, 2020, Accepted: March 31, 2020, Available Online: April 01, 2020

\begin{abstract}
In this paper, expanded perlite based particulate composites for the application in building insulation board are studied for compressive behaviour. Composites with a density range from 0.452 to $0.640 \mathrm{~g} / \mathrm{cm}^{3}$ are manufactured using floatation method by varying binder content (sodium silicate solution and corn starch as binder) and the degree of compaction. Compressive strength and modulus are investigated based on two manufacturing parameters (i.e. Compaction ratio and Water/SSS ratio) and the density of the composites. Compressive strength and modulus were found to be linearly dependent on the density however the trend for compressive strength and modulus were found to be different. The change of compressive modulus with respect to increasing density is found to be different for different compaction ratio which is not significant in the case of compressive strength. The range of specific compressive strength of the composites from 4.27 to $5.08 \mathrm{MPa} /\left(\mathrm{g} / \mathrm{cm}^{3}\right)$ was found to be suitable for the building insulation board application when compared with existing literature.
\end{abstract}

Keywords: Expanded Perlite; Sodium Silicate Solution; Corn Starch; Building Insulation Board; Compressive Strength; Compressive Modulus.

This work is licensed under a Creative Commons Attribution-NonCommercial 4.0 International

\section{Introduction}

Perlite is typically made by the hydration of obsidian [1] and can be expanded to form cellular structure [2], [3]. The expansion can be done at a temperature of $649-816{ }^{\circ} \mathrm{C}$ with the removal of water molecules [4]. Expanded perlite [5]-[7] particles are porous, lightweight, fire resistant, insulator to sound and heat, chemically inert and cheap. In applications for interior walls and ceilings, the thermal conduction is important for energy saving during heating and cooling and the weight of a material is a significant factor for transportation and installation because of the large amount of material to be handled. So, expanded perlite particles may be a potential constituent material for the development of such building material because of its lightweight and low cost. Researchers have been working on expanded perlite particle based building boards such as perlitic insulation board by Hill [8], building boards made of fibre/asphalt coated perlite by Miscall and Rahr [9], mineral board by Sherman and Cameron [10], perlite/starch composite by Shastri and Kim [11], gypsum/perlite composites by Vimmrova [12], Perlite/sodium silicate composite by Arifuzzaman and Kim [13] etc. However there is an enormous scope to develop perlite based building materials with the use of more cheap and easily available binding materials such as corn starch as a reinforcement to sodium silicate solution. Sodium silicate solution is fire resistant and corn starch is a good binder.

Therefore, the objectives of this paper are to consolidate perlite based particulate composites using the novel floatation method [11] with the use of gelatinized corn starch as a reinforcement to sodium silicate solution, to investigate compressive properties of the composites and to find the suitability of the composite for building board applications.

\section{Materials and Method}

\subsection{Expanded Perlite}

Expanded perlite particles are purchased from China and separated into various particle size groups (1-2 mm, 2-3 mm and 3-4 mm) using sieves. Particle size group 3-4 mm were chosen for this work. According to the data sheet provided by the manufacturer expanded perlite contained $71-74 \%$ Silicon Oxide, 12-13\% Aluminium Oxide, 3-4\% Sodium Oxide, 3-5\% Potassium Oxide, $1.2 \%$ Calcium Oxide, $1.0 \%$ Ferric Oxide and some diminutive amount of Titanium Oxide and Magnesium Oxide. The bulk density of perlite particles was measured using a measuring cylinder of 100 $\mathrm{cm}^{3}$ capacity into which particles were first poured slowly with a spoon. Then the mass of particles were recorded. The bulk density of the expanded perlite was calculated using the equation

Bulk density, $\rho=$ (the mass of perlite particles / the volume of perlite particles) $\mathrm{g} / \mathrm{cm}^{3}$.

The average bulk density of 3-4 mm perlite particles was found to be $0.187 \mathrm{~g} / \mathrm{cm}^{3}$.

\subsection{Sodium Silicate Solution (SSS) and Starch}

Sodium silicate solution was used as a binder having a density of $1.39 \mathrm{~g} / \mathrm{cm}^{3}$. It is necessary to determine the solid content of sodium silicate solution after dehydration to properly characterize it for reproducibility of results. SSS was diluted with drinking water at different ratio [See Table 1] and then stirred for 2-3 minutes. The diluted SSS of fixed mass are then dried inside an oven at $120^{\circ} \mathrm{C}$ until no mass change is noticed. 
The difference in mass of diluted SSS and solid sodium silicate after dehydration indicates the solid contents in diluted SSS. The solid contents for various Water to SSS ratios are given in Table 1. It is seen that the solid content is affected by dilution and decreased with increasing Water/SSS ratio. Solid content on SSS without dilution is found to be $48.60 \%$.

Table 1 Solid content in SSS with various dilution

\begin{tabular}{ccccc}
\hline Sample & $\begin{array}{c}\text { Mass of } \\
\text { SSS, g }\end{array}$ & $\begin{array}{c}\text { Mass of } \\
\text { water, g }\end{array}$ & $\begin{array}{c}\text { Water to } \\
\text { SSS } \\
\text { ratio }\end{array}$ & $\begin{array}{c}\text { Solid } \\
\text { content in } \\
\text { diluted } \\
\text { SSS, \% }\end{array}$ \\
\hline 01 & 5 & 0.0 & 0 & 48.60 \\
02 & 5 & 5.0 & 1 & 26.70 \\
03 & 5 & 10.0 & 2 & 19.80 \\
04 & 5 & 15.0 & 3 & 14.50
\end{tabular}

To determine solid content in corn starch solution, $100 \mathrm{~g}$ of water was taken into a beaker and different amount of starch powder was added to it and stirred the solution at above $70^{\circ} \mathrm{C}$ for 30 minutes and a clear solution is obtained as a result of polymerization. After polymerization $20 \mathrm{~g}$ solution was taken into an empty test tube and put it into an oven at $120^{\circ} \mathrm{C}$ until there is no mass change due to water loss. The solid contents obtained for various starch content in water is given in Table 2 and in Fig. 1. It is seen that solid content increased linearly with increasing starch content in binder but not all starch powder are gelatinized for the set temperature and time in this work which is reflected in the loss percentage. The loss percentage indicates that only about $66.34 \%$ starch powder was gelatinized due to polymerization.

Table 2 Determination of solid content in Starch

\begin{tabular}{cccccc}
\hline Sample & $\begin{array}{c}\text { Mass of } \\
\text { Starch, } \\
\mathrm{g}\end{array}$ & $\begin{array}{c}\text { Mass } \\
\text { of } \\
\text { water, } \\
\mathrm{g}\end{array}$ & $\begin{array}{c}\text { Starch } \\
\text { content in } \\
\text { binder, } \%\end{array}$ & $\begin{array}{c}\text { Solid } \\
\text { content, } \\
\%\end{array}$ & $\begin{array}{c}\text { Loss, } \\
\%\end{array}$ \\
\hline 1 & 0.50 & 100 & 0.498 & 0.35 & 29.65 \\
2 & 1.00 & 100 & 0.990 & 0.65 & 34.35 \\
3 & 1.50 & 100 & 1.478 & 0.95 & 35.72 \\
4 & 2.00 & 100 & 1.961 & 1.25 & 36.25 \\
5 & 2.50 & 100 & 2.439 & 1.65 & 32.35 \\
\hline
\end{tabular}

An analogous procedure was followed to measure the solid content in combined solution i.e. diluted sodium silicate solution with starch powder according to the combination given in Table 3. SSS was added to gelatinized starch for making combined solution. The solid content in the prepared solution is also found to be decreased with increasing Water/SSS ratio but the solid content in the combined solution is slightly higher due to the addition of starch.

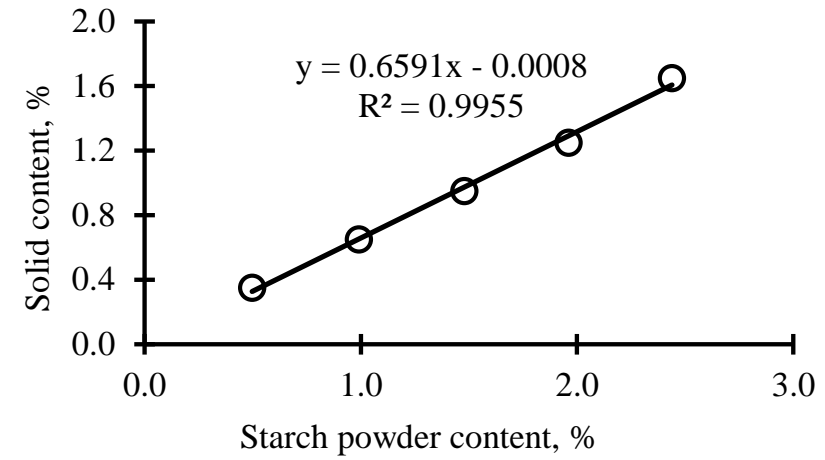

Fig. 1 Solid content in the gelatinized starch solution as a function of starch powder in water

Table 3 Determination of solid content in SSS + Starch

\begin{tabular}{cccccc}
\hline Sample & $\begin{array}{c}\text { Mass } \\
\text { of } \\
\text { starch, } \\
\mathrm{g}\end{array}$ & $\begin{array}{c}\text { Mass } \\
\text { of } \\
\text { water, } \\
\mathrm{g}\end{array}$ & $\begin{array}{c}\text { Mass } \\
\text { of } \\
\text { SSS, } g\end{array}$ & $\begin{array}{c}\text { Water/SSS } \\
\text { ratio }\end{array}$ & $\begin{array}{c}\text { Solid } \\
\text { content, } \\
\%\end{array}$ \\
\hline 1 & 1.50 & 100 & 100.00 & 1 & 28.10 \\
2 & 1.50 & 100 & 50.00 & 2 & 22.10 \\
3 & 1.50 & 100 & 33.33 & 3 & 16.85 \\
4 & 1.50 & 100 & 25.00 & 4 & 12.60 \\
\hline
\end{tabular}

2.3 Specimen Preparation Process

The process of manufacturing composite consists of binder preparation, mixing, compaction, and drying steps. The binder is prepared by mixing a fixed amount of corn starch (see Table 3 for mix proportion) with water and then continuously stirring at $70^{\circ} \mathrm{C}$ for 30 minutes for gelatinization. Later SSS was added to the gelatinized solution according to Table 4. A PVC pipe having diameter $42 \mathrm{~mm}$ was taken and one side of the opening was blocked by a plastic wire net. Then different mass of expanded perlite particle for different compaction ratio (Compaction ratio $=$ the ratio of the volume of perlite before compaction and final specimen volume) was poured into the PVC pipe. The required expanded perlite mass was calculated using equation

Mass of perlite particle required $=$ bulk density of perlite $\times$ specimen final volume $\times$ compaction ratio.

The PVC pipe with expanded perlite is dipped and soaked into the binder solution until all perlite particle get wet before transferring the PVC mould for compaction. During compaction, 2/3 of compaction stroke was applied from the top side and rest from bottom side of the mould to obtain uniform density through the thickness. The specimen was removed from the mould by pushing with the plunger. The specimen was kept on a paper towel and performed a frequent shifting of specimen to ensure there is no binder in the towel. Then the wet mass of the specimen was taken and transferred into an oven for drying at $120^{\circ} \mathrm{C}$ for 24 hours. The dry mass was recorded when the specimen reached room temperature. At least three test specimens were prepared for each combination of compaction ratios (i.e. 2.5, 3.0 and 3.5) and Water to SSS ratios (i.e. 1, 2, 3, and 4). 
Table 4 Density, compressive strength and compressive modulus of manufactured composites for various combinations of compaction ratios and Water to SSS ratios.

\begin{tabular}{cccccccccc}
\hline \multirow{2}{*}{ Water/SSS ratio } & \multicolumn{3}{c}{ Density, $\mathrm{g} / \mathrm{cm}^{3}$} & \multicolumn{3}{c}{ Compressive strength, MPa } & \multicolumn{2}{c}{ Compressive modulus, MPa } \\
\cline { 2 - 10 } & C.R=2.5 & C.R.=3.0 & C.R.=3.5 & C.R=2.5 & C.R.=3.0 & C.R.=3.5 & C.R=2.5 & C.R.= 3.0 & C.R.= 3.5 \\
\hline 1 & 0.478 & 0.538 & 0.640 & 2.23 & 2.53 & 3.25 & 21.22 & 33.15 & 54.89 \\
2 & 0.470 & 0.510 & 0.607 & 2.12 & 2.44 & 3.04 & 32.87 & 37.29 & 49.13 \\
3 & 0.463 & 0.491 & 0.578 & 2.04 & 2.32 & 2.82 & 37.54 & 43.26 & 47.67 \\
4 & 0.452 & 0.480 & 0.554 & 1.93 & 2.23 & 2.48 & 48.44 & 46.23 & 44.34 \\
\hline
\end{tabular}

\subsection{Density Measurement}

The final height, diameter and mass of the specimen was measured to calculate the density using the equation,

Density $=$ Final mass of the specimen $/$ the volume of the specimen.

\subsection{Compression Test}

The compression test was carried out in the Universal Testing Machine with a load cell of capacity $50 \mathrm{kN}$ and digital data acquisition system at a displacement rate of $5 \mathrm{~mm} / \mathrm{min}$. At least three specimens were tested. The compressive strength was calculated using the equation

Compressive strength $=$ Peak force $/$ cross sectional area of the specimen.

The compressive modulus was measured from the slope of the most linear part of the stress versus strain curve before peak load.

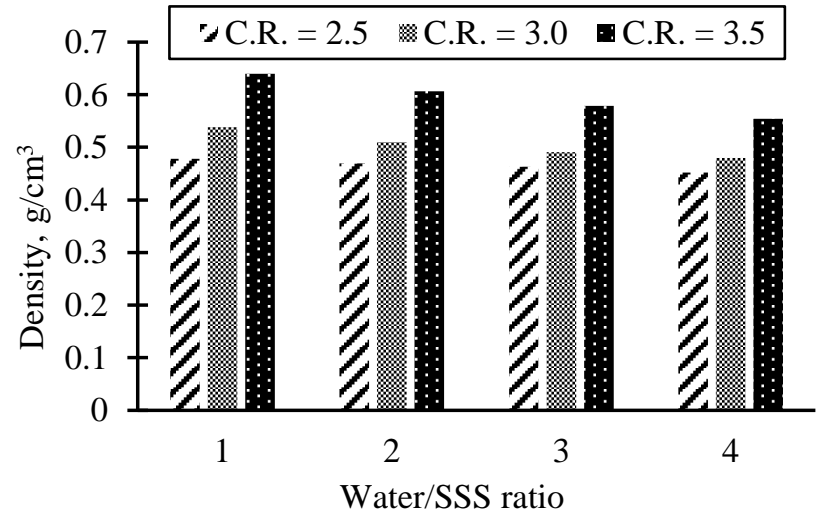

Fig. 2 Density of the manufactured composites for various combinations of compaction ratios and Water/SSS ratios

\section{Results and Discussion}

The physical and mechanical properties of the manufactured composites for various combinations of compaction ratios and Water/SSS ratios are listed in Table 4. Density is plotted as a bar chart for various Water/SSS ratio and compaction ratio in Fig. 2. It is observed that the density of the composites increased with increasing compaction ratio for all Water/SSS ratio expectedly because higher compaction means higher amount of perlite and binder in the composites. On the other hand, for a constant compaction ratio, the density of the composites showed a decreasing trend when Water/SSS ratio increased for all compaction ratio (see Table 4). A high Water/SSS ratio indicates less amount of solid in the binder (see Table 4) which reduced the density of the specimens for fixed amount of perlite.

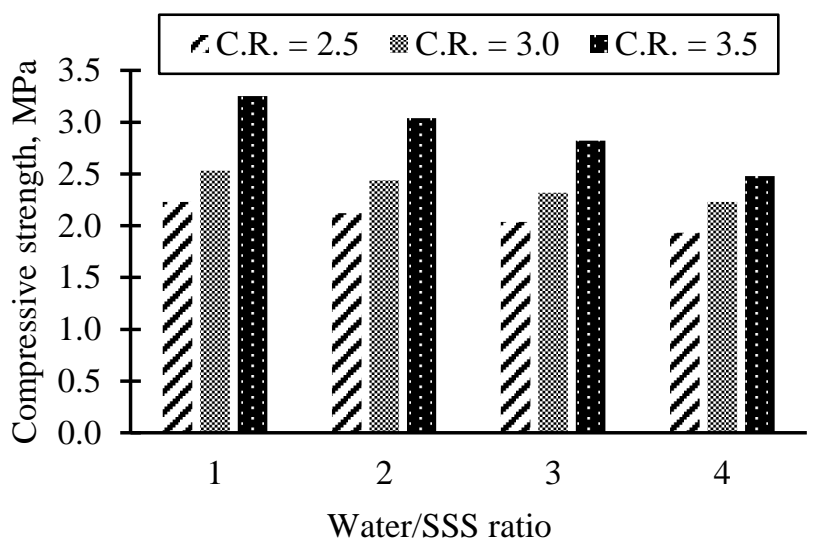

Fig. 3 Compressive strength of the manufactured composites for various combinations of compaction ratios and Water/SSS ratios.

Compressive strength of composites are plotted in Fig. 3 to see the effect of Water/SSS ratio and compaction ratio. The compressive strength increased with increasing compaction ratio for all Water/SSS ratio and it decreased with increasing Water/SSS ratio for all compaction ratio. For a constant Water/SSS ratio, when compaction ratio is increased the pores of cellular perlite particles are reduced which causes an increase in compressive strength. Since the increase in Water/SSS ratio for a constant compaction ratio reduces the amount of binder in the composite, it causes the reduction of load carrying capacity of the composite and hence compressive strength decreased.

A bar chart is plotted in Fig. 4 for compressive modulus of manufactured composites to investigate the effect of Water/SSS ratio and compaction ratio. The compressive modulus appeared to increase with increasing compaction ratio for Water/SSS ratio $=1$ to 3 but for Water/SSS ratio 4 the trend is reversed. As the Water/SSS ratio increased from 1 to 3 , the rate of increase in compressive modulus is decreased and become negative when Water/SSS ratio $=4$. On the other hand, compressive modulus increased with increasing Water/SSS ratio for compaction ratio 2.5 and 3.0 but for compaction ratio 3.5 it decreased. The highest compressive modulus is notices for composite with compaction ratio=3.5 and Water/SSS ratio=1. For compaction ratio 2.5 and 3.0, the lesser the binder content in the composite the higher the compressive modulus and the rate of increase in compressive 
modulus with increasing Water/SSS ratio is decreased when compaction ratio is increased from 2.5 to 3.0. Therefore the rate of increase in compressive modulus with decreasing binder content is suppressed with increased compaction ratio and as part of the continuation of suppression the rate become negative at compaction ratio 3.5 .

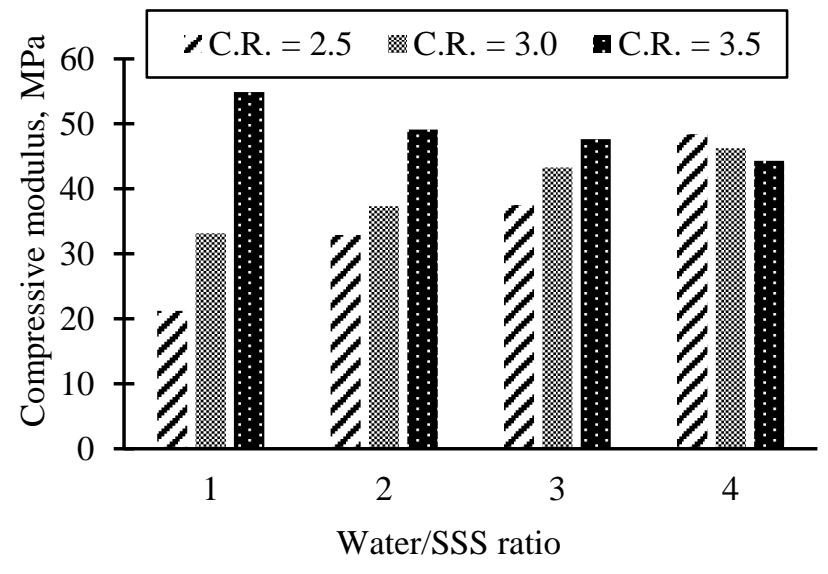

Fig. 4 Compressive modulus of the manufactured composites for various combinations of compaction ratios and Water/SSS ratios.

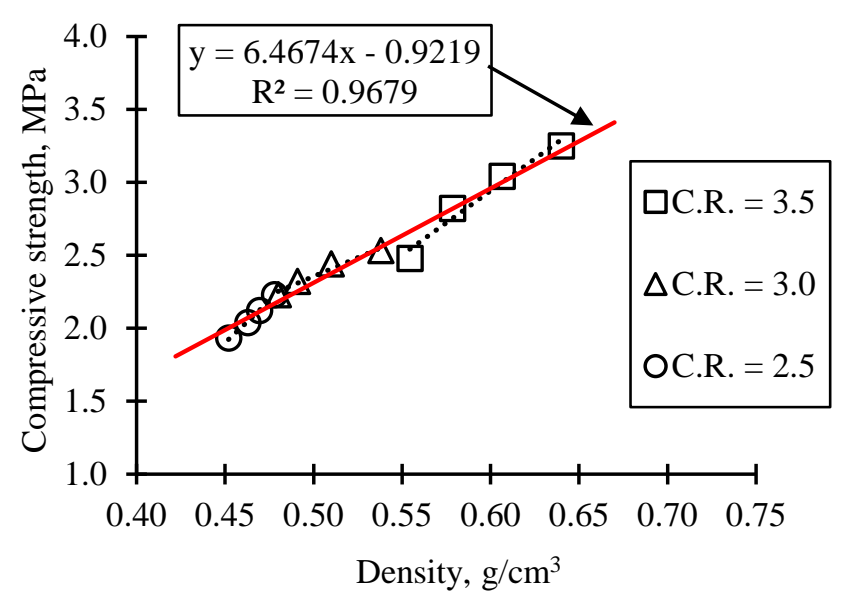

Fig. 5 Compressive strength of the composites as a function of density for various compaction ratios

Compressive strength is plotted as a function of density for various compaction ratio in Fig. 5. It is observed that compressive strength increased linearly with increasing density for all compaction ratio and the higher compaction ratio results higher compressive strength. The least square line and correlation coefficient $\left(\mathrm{R}^{2}\right)$ were $\mathrm{y}=11.468 \mathrm{x}-3.2598$ and 0.9934 for C.R. $=2.5 ; \mathrm{y}=5.1402 \mathrm{x}-0.2143$ and 0.9599 for C.R. =3.0; and $y=8.7715 x-2.3207$ and 0.9635 for C.R. $=3.5$. It is also interesting to see that compressive strength increased linearly with increasing density with least square line $\mathrm{y}=$ $6.4674 \mathrm{x}-0.9219$ and correlation coefficient $\mathrm{R}^{2}=0.9679$ irrespective to the compaction ratio. The high correlation coefficient indicates high linearity. So, it is apparent that the compressive strength is dependent on the density of the composite material although the density of the composite itself is a function of the manufacturing parameters as discussed earlier.
Compressive modulus is given as a function of density for various compaction ratio in Fig. 6. Compressive modulus decreased linearly with increasing the density of the composite for compaction ratio 2.5 and 3.0 but it showed an opposite trend for compaction ratio 3.5. The least square lines and correlation coefficients $\left(\mathrm{R}^{2}\right)$ are $\mathrm{y}=-1021.6 \mathrm{x}+510.68$ and 0.993 for C.R. $=2.5 ; \mathrm{y}=-227.94 \mathrm{x}+155.04$ and 0.984 for C.R. $=3.0$; and $\mathrm{y}=$ 117.12x-20.66 and 0.980 for C.R. $=3.5$. It is also observed that the rate of decrease in compressive modulus lessened when compaction ratio increased from 2.5 to 3.0 and to follow the trend eventually at compaction ratio 3.5 the compressive modulus increased linearly with increasing the density.

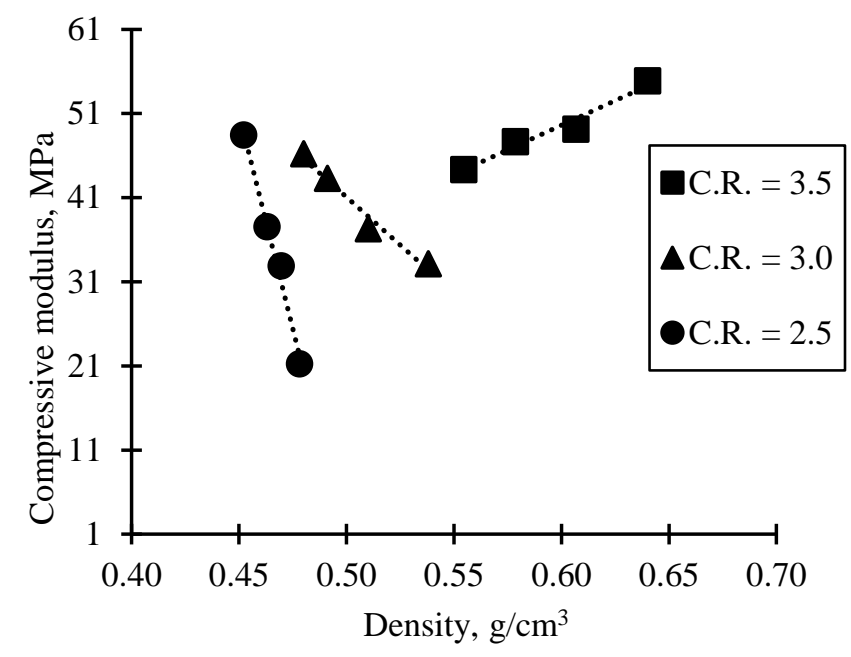

Fig. 6 Compressive modulus of the composites as a function of density for various compaction ratios

Now, it is necessary to outline compressive properties along with the density of some building board materials available in the literature for the purpose of comparison. Colak [14] reported a range of specific compressive strength of building board from 0.62 to $2.03 \mathrm{MPa} /\left(\mathrm{g} / \mathrm{cm}^{3}\right)$, Arifuzzaman and Kim [13] showed a range from 0.8 to $5.37 \mathrm{MPa} /\left(\mathrm{g} / \mathrm{cm}^{3}\right)$, Skujans et al. [15] found a range from 1.1 to $3.1 \mathrm{MPa} /\left(\mathrm{g} / \mathrm{cm}^{3}\right)$ and Vimmrova et al. [12] stated a range from 1 to 3.86 $\mathrm{MPa} /\left(\mathrm{g} / \mathrm{cm}^{3}\right)$ which are highly comparable with the current composites with a range from 4.27 to $5.08 \mathrm{MPa} /\left(\mathrm{g} / \mathrm{cm}^{3}\right)$. So, the composites that are studied here are suitable for application in building insulation board.

\section{Conclusion}

Expanded perlite based particulate composites with a range of density from 0.452 to $0.640 \mathrm{~g} / \mathrm{cm}^{3}$ were manufactured by varying the degree of compaction and binder contents to study compressive properties. Compressive strength and modulus are analysed based on manufacturing parameters (i.e. Compaction ratio and Water/SSS ratio) and the density of the composites. Compressive strength is found to be increased with increasing compaction ratio, binder content and the density of composites. Compressive modulus decreased with increasing density for low compaction ratio but at high compaction ratio it showed an increasing trend. The composites were found to be suitable for building board applications based on the range of specific compressive strength from 4.27 to $5.08 \mathrm{MPa} /\left(\mathrm{g} / \mathrm{cm}^{3}\right)$ when compared with available literature. 


\section{Acknowledgements}

Authors acknowledge the support from the Laboratory staffs of the Department of Mechanical Engineering, KUET, Bangladesh during specimen manufacturing process and testing.

\section{References}

[1] Luongo JS, inventor; Advanced Construction Materials Corp, assignee. Strengthened, light weight wallboard and method and apparatus for making the same. United States patent US 6,251,979. 2001 Jun 26.

[2] Yilmazer S, Ozdeniz MB. The effect of moisture content on sound absorption of expanded perlite plates. Building and Environment. 2005 Mar 1;40(3):311-8.

[3] Dube WP, Sparks LL, Slifka AJ. Thermal conductivity of evacuated perlite at low temperatures as a function of load and load history. Cryogenics. 1991 Jan 1;31(1):3-6.

[4] Reka AA, Pavlovski B, Lisichkov K, Jashari A, Boev B, Boev I, Lazarova M, Eskizeybek V, Oral A, Makreski P. Chemical, mineralogical and structural features of native and expanded perlite from Macedonia. Geologia croatica. 2019 Oct 31;72(3):215-21.

[5] Singh M, Garg M. Perlite-based building materials-a review of current applications. Construction and Building Materials. 1991 Jun 1;5(2):75-81.

[6] Burriesci N, Arcoraci C, Antonucci P, Polizzotti G. Physico-chemical characterization of perlite of various origins. Materials Letters. 1985 Jan 1;3(3):103-10.
[7] Johnstone SJ. Minerals for the chemical and allied industries. Geological Magazine. 1954 Oct;91(5):408-9.

[8] Hill JA, inventor; Johns Manville Corp, assignee. Perlitic insulating board. United States patent US 4,126,512. 1978 Nov 21.

[9] Jack M, Rahr CE, inventors; SGL Carbon Corp, assignee. Building board of fiber and asphalt coated perlite. United States patent US 2,626,864. 1953 Jan 27.

[10] Sherman N, Cameron JH, inventors; Conwed Corp, assignee. Method of manufacturing improved mineral board. United States patent US 4,297,311. 1981 Oct 27.

[11] Shastri D, Kim HS. A new consolidation process for expanded perlite particles. Construction and Building Materials. 2014 Jun 16;60:1-7.

[12] Vimmrova A, Keppert M, Svoboda L, Černý R. Lightweight gypsum composites: Design strategies for multi-functionality. Cement and Concrete Composites. 2011 Jan 1;33(1):84-9.

[13] Arifuzzaman M, Kim HS. Novel mechanical behaviour of perlite/sodium silicate composites. Construction and Building Materials. 2015 Sep 15;93:230-40.

[14] Colak A. Density and strength characteristics of foamed gypsum. Cement and Concrete Composites. 2000 Jun 1;22(3):193-200.

[15] Skujans J, Vulans A, Iljins U, Aboltins A. Measurements of heat transfer of multi-layered wall construction with foam gypsum. Applied Thermal Engineering. 2007 May $1 ; 27(7): 1219-24$. 